\title{
ЭТНОКУЛЬТУРАЛЬНАЯ ПСИХИАТРИЯ
}

\author{
УДК 616.895.4:616.89-008.441.44-053.6(571.6)(510)
}

Для цитирования: Логинов И.П., Солодкая Е.В., Савин С.З. Психопатологические проявления и особенности течения депрессивных расстройств в подростковом возрасте: транскультуральные клинические наблюдения. Сибирский вестник психиатрии и наркологии. 2021; 1 (110): 78-84. https://doi.org/10.26617/1810-3111-2021$1(110)-78-84$

\section{Психопатологические проявления и особенности течения депрессивных расстройств в подростковом возрасте: транскультуральные клинические наблюдения}

\section{Логинов И.П.', Солодкая Е.В.' ${ }^{1}$, Савин С.3. ${ }^{2}$}

\author{
1 ФГБОУ ВО «Дальневосточный государственный медищинский университет» Минздрава России \\ Россия, 680000, Хабаровск, ул. Муравьева-Амурского, 35 \\ ${ }^{2}$ ФГБОУ ВО «Тихоокеанский государственный университет» \\ Россия, 680035, Хабаровск, ул. Тихоокеанская, 136
}

\section{PEЗЮME}

Введение. Актуальность проблемы депрессивных расстройств, проявляющихся в подростковом возрасте, определяется их высокой распространенностью, трудностью распознавания аффективной патологии на ранних стадиях заболевания и высоким суицидальным риском. Цель: выявление и систематизация в рамках полифакториальной концепции клинических, социальных и личностных психологических триггеров, способствующих формированию депрессивных расстройств у подростков. Методы: клинико-психопатологический, клинико-психологический (с использованием анкеты-интервью, включая данные анамнеза), клиникодинамический, экспериментально-психологический, социально-психологический, метод наблюдения, метод обратного перевода. В основу методологического подхода положен принцип этносоциокультуральной детерминированности возникновения и клинического течения депрессивных расстройств с учетом их особенностей в различных национальных культурах. Результаты. Выявлены клинические варианты депрессивного синдрома на примере двух клинических наблюдений (18-летняя девушка и 19-летний юноша, средний возраст $18,5 \pm 0,5$ года). Установлено, что на формирование депрессивной симптоматики патопластическое и патогенетическое влияние оказывали два основных фактора - неблагоприятный психологический микроклимат в семье и деструктивный тип воспитания. Пациентам были выставлены клинические диагнозы: расстройство адаптации, смешанная тревожная и депрессивная реакция. Заключение. Два клинических наблюдения подростковых депрессивных расстройств, проведенные в России (Хабаровск) и Китае (Харбин), показали, что в анамнезе обследуемых подростков имеет место наследственная отягощенность психическими расстройствами у близких родственников. Значимая роль в формировании депрессивных состояний принадлежит испытываемым подростками негативным факторам - длительному психологическому дискомфорту и неудовлетворенности в связи с неблагоприятной атмосферой в семье, а также этническому типу воспитания.

Ключевые слова: депрессивные расстройства, проявления подростковой депрессии, мотивы суицидального поведения у подростков, этнокультуральная парадигма, сравнительное транскультуральное исследование (Россия и Китай), описание и анализ клинических случаев.

ВВЕДЕНИЕ

Актуальность проблемы депрессивных расстройств (ДР), проявляющихся начиная с подросткового возраста, определяется их высокой распространенностью, трудностью распознавания этой патологии на ранних стадиях заболевания и высоким суицидальным риском $[1,4,6,8,12]$. По эпидемиологическим данным, распространенность ДР среди населения в возрасте 15-19 лет колеблется от $8 \%$ до 20\% и составляет свыше $50 \%$ от общего числа случаев психических расстройств среди подростков и молодежи, причем пик самоубийств приходится на возрастную группу 15-25 лет [3, 12, 15, 17]. Исследования показывают, что аффективная патология представляет собой гетерогенную группу расстройств, и их диагностика и лечение всё еще являются трудной клинической задачей [2, 11, 14, 17, 19]. 
В то же время имеющиеся научные труды, посвященные проблеме ДР в подростковом контингенте, указывают на значительный клинический полиморфизм и атипичность этих состояний $[4,7$, 8]. Выявлены конкретные варианты депрессивного синдрома, в формировании клинической картины которого особую роль авторы отводят патопластическому и патогенетическому влиянию возрастного фактора. Некоторые исследователи $[9,13,15]$ при изучении депрессивной симптоматики у лиц подросткового и юношеского возрастов ограничиваются сосредоточением внимания на так называемых объективных методах (шкалах, опросниках), игнорируя в ряде случаев психодиагностический и психопатологический методы и клинико-нозологическую оценку болезни в целом. Вместе с тем отечественным исследователям, использующим в основном методы клинического и психопатологического анализа, не хватает общесогласованной интегративности, так как они не применяют надлежащие методики размерности, а также обходят вниманием корреляцию психопатологических данных с генетическими параметрами [7, 19]. В то время как в большинстве исследований приводится обоснование целесообразности изучения с позиций биопсихосоциальной модели психобиологических (в частности психогенетических) особенностей подросткового возраста, определяющих пубертатную фазу созревания, с целью последующего решения терапевтических проблем, поскольку их недооценка приводит к просчетам при построении стратегии психофармакотерапии и психосоциореабилитации этой группы пациентов [2, 7, 9, 12, 17, 19].

\section{ЦЕЛЬ ИССЛЕДОВАНИЯ}

Выявление и систематизация в рамках полифакториальной концепции клинических, социальных и личностных психологических триггеров, способствующих формированию депрессивных расстройств у подростков.

\section{МАТЕРИАЛ И МЕТОДЫ}

В качестве основных методов обследования использовались клинико-психопатологический [9, $11,13]$, клинико-психологический (с использованием анкеты-интервью, включая данные анамнеза) [10, $13]$, клинико-динамический $[14,15,16]$, экспериментально-психологический $[17,18,19,20]$, социально-психологический, метод наблюдения и метод обратного перевода [1, 3]. Основу исследования составляли клинические дефиниции и диагностические критерии МКБ-10 и DSM-IV. Дополнительно применялись формализованные карты исследования, адаптированные для российской и китайской популяций: шкалы депрессии (HDRS-17) и тревоги (HARS) Гамильтона, предназначенные для количественной оценки психопатологического статуса пациентов [3, 10].
Динамика депрессивного расстройства отслеживалась на основе интерпретации результатов редукции показателей соответствующих субшкал $[16,18]$. Крайне важным моментом являлся сбор информации во время бесед с родственниками подростков, от которых можно было получить объективные сведения о развитии субклинических и клинических психических проявлений. Клинико-социальный метод использовался для оценки выявления факторов риска в макрои микросоциальной сферах жизнедеятельности подростков. При этом к макросоциальным факторам относились социальные условия, непосредственно обусловленные социальноэкономической и политической структурой государства. Микросоциальные факторы включали близкое окружение подростка (в том числе условия проживания в семье), отношения в школьном коллективе, разнообразных неформальных группах и объединениях. В основу комплексного методологического подхода положена концепция этносоциокультуральной детерминированности возникновения и клинической картины депрессивных расстройств с учетом их особенностей в различных национальных культурах $[1,3,5,8,9$, 14].

\section{РЕЗУЛЬТАТЫ И ОБСУЖДЕНИЯ}

В результате обсервационного наблюдения описаны клинические варианты депрессивного синдрома на примере двух больных - 18 лет женского пола и 19 лет мужского пола (средний возраст 18,5 $\pm 0,5$ года). Приводим далее дескриптивные результаты наблюдений.

Клинический пример № 1. Больная Е., 18 лет, была доставлена в психиатрическую больницу из дома после суицидальной попытки.

Анамнез жизни: родилась в Хабаровске вторым ребенком из двух детей, в семье служащих. Воспитывалась родителями в полной семье. Наследственность психопатологически отягощена у родственников, суицидов в семье не отмечено. Сведениями о течении беременности и родах матери не располагает. Ранее развитие без особенностей. Несколько лет назад мать погибла, отец повторно состоит в гражданском браке. Проживает во второй семье отца. В школу пошла с 7 лет, училась посредственно, классы не дублировала, нарушений поведения и игнорирования школьных и домашних обязанностей не наблюдалось. По окончании 11 классов нигде не работает и не учится, живет за счет отца. Не замужем, детей нет. Черепно-мозговые травмы, пароксизмальные реакции, нейроинфекций в анамнезе отсутствуют. Вирусный гепатит, венерические заболевания, туберкулез отрицает. Гемотрансфузии не проводились. Аллергических реакций не отмечалось. Курит с 14 лет, периодически алкоголизируется. Сообщила о двукратном приеме наркотиков 
(инъекционно), так как было «любопытно», хотелось самой понять «какой в этом интерес»).

Анамнез заболевания: в течение последнего года неоднократно предпринимала различные суицидальные попытки - резала вены, угрожала отравиться, пыталась повеситься. К психиатрам не обращалась. Состояния возбуждения и суицидальные тенденции возникают на фоне конфликтных отношений с отцом из-за нежелания и отказа работать или продолжать обучение. Кроме того, познакомилась и последние несколько месяцев встречается с парнем, употребляющим опиаты, отец об этом знает и категорически запрещает поддерживать отношения «с этим наркоманом».

Накануне госпитализации произошел очередной конфликт с отцом, утратив сдержанность, он угрожал отправить её жить к бабушке в другой город. Всю ночь проплакала, не могла успокоиться, утром продолжала высказывать суицидальные намерения. Нынешнее ухудшение психического состояния отмечает в течение последних 3 месяцев. Стала чувствовать себя грустной и подавленной («никому не нужна и не интересна»). Не могла заставить себя заниматься обычными повседневными делами: «Не хочу ничего делать, только лежать, хотя вроде и силы есть». Стала часто просыпаться (в 4-5 часов утра) и «пока никто не мешает» с тревогой представляла «мрачные перспективы». После этого стала размышлять о наиболее безболезненных способах самоубийства, хотя «всерьез к этому не относилась» и «думала об этом на всякий случай». Совершила суицидальную попытку - порезала вены на предплечье, рана ушита в травмпункте. Так как пациентка продолжала оставаться крайне подавленной и некритичной к своему состоянию, была переведена в психиатрическую больницу, где был поставлен диагноз: расстройство адаптации, пролонгированная депрессивная реакция, суицидальная попытка.

Анализ наблюдения: на основании психологического обследования отмечены следующие результаты: шкала депрессии Гамильтона - 15 баллов (умеренная депрессивная симптоматика), шкала тревоги Гамильтона - 20 баллов (умеренная тревожная симптоматика). Заключение психолога: состояние психологической дезадаптации с депрессией, тревожностью и суицидальными мыслями на фоне конфликта с отцом. Психосоциальный статус: нарушение отношений в родительской семье (смерть матери), отсутствие поддержки со стороны отца.

Впервые суицидальные мысли возникли остро, спонтанно на фоне психотравмирующей ситуации и спровоцировали импульсивную суицидальную попытку. Во второй раз суицидальная настроенность обостряется на фоне депрессии, вызванной хронической психической травмой, что способствовало переходу суицидальных мыслей на уровень реализации суицидальных намерений. Тяжесть тревожно-депрессивной симптоматики пациентки подтверждена данными психометрического исследова- ния с использованием шкалы Гамильтона (HARS). Клинический диагноз: расстройство адаптации, тревожно-депрессивная реакция.

Клинический пример № 2. Больной БКР, 19 лет. Поступил в Первый специальный госпиталь (Харбин) после суицидальной попытки.

Анамнез жизни: отягощенный семейный анамнез по психическим расстройствам. Со слов матери, её дальняя родственница страдает психическим расстройством, родной отец пациента злоупотреблял курением конопли, проходил стационарное лечение в Первом специальном госпитале (Харбин) анонимно много лет назад. Родился в семье рабочих, проживавших в г. Хэган провинции Хэйлунцзян. Является единственным ребенком в семье. Раннее развитие без особенностей, в психофизическом развитии не отставал, постоянно находился под родительской опекой. Учебу в школе начал в 7-летнем возрасте, учился хорошо, не прикладывая особых усилий, однако особого стремления достичь успехов в учебе и инициативности не проявлял. Был общительным, подвижным, имел много друзей, в отношениях со сверстниками был повышенно эмоциональным, но быстро отходчивым. К новой обстановке привыкал быстро, без затруднений заводил новые знакомства, поддерживал товарищеские отношения со сверстниками. Вне учебы старался помогать родителям по хозяйству, занимался спортом. Закончил начальную школу (6 лет), затем неполную среднюю и среднюю (по 3 года). В 19-летнем возрасте поступил на факультет иностранных языков педагогического института, где изучает английский и русский языки. Учится на хорошо и отлично. К вредным привычкам (алкоголь, наркотики) относится отрицательно. Нейроинфекций не было. Вирусный гепатит, венерические заболевания, туберкулез отрицает. Гемотрансфузии не проводились. Аллергических реакций не отмечалось.

Анамнез заболевания: психическое состояние, со слов матери, изменилось с октября 2013 г., когда стал подвергаться обидным насмешкам, унижению, угрозам, преследованиям со стороны одногруппников, преимущественно девочек. Эмоциональная агрессия перешла в физическое насилие - избивали, пинали ногами. Со слов пациента, нейтрально отновившиеся к нему одногруппники не защищали, возможно даже поощряли такие действия. Стал подавленным, отстраненным, задумчивым, высказывал мысли о нежелании жить. Ранее совершал суицидальные действия - пытался отравиться таблетками. После того как в очередной раз подвергся угрозам и унижению, совершил повторную суицидальную попытку - принял большое количество неизвестных таблеток, пытался резать вены. Мать вызвала скорую помощь, промыли желудок на дому. Не был госпитализирован в стационар, куда родственники обратились в порядке скорой помощи, была рекомендована консультация психотерапевта. Настроение оставалось сниженным, чувствовал беспомощность и апатию ко всему. После уговоров матери 
обратился за психиатрической помощью, после информированного согласия был госпитализирован.

Анализ наблюдения: состояние в отделении оставалось удовлетворительным. Первое время настроение было неустойчивым, переживал из-за госпитализации, постепенно эмоциональное состояние выровнялось, чувствовал себя «нормальным». Вместе с тем суицидальные попытки формально расценивал как демонстративные, относился к ним со слабой критикой. В беседе с врачом отвечал односложно, был зажат. В своих суждениях опирался на мнение матери, что связано с многолетним контролирующим с гиперопекой воспитанием в семье.

Было проведено психологическое обследование. По данным психометрической диагностики получены следующие количественные показатели: шкала депрессии Гамильтона - 16 баллов (умеренная депрессивная симптоматика), шкала тревоги Гамильтона - 18 баллов (умеренная тревожная симптоматика). Заключение психолога: состояние психологической дезадаптации с депрессией, тревожностью, суицидальными мыслями на фоне конфликта с сокурсниками. Психосоциальный статус: нарушение отношений в родительской семье (развод родителей), отсутствие опоры и поддержки отца. Клинический диагноз: расстройство адаптации, смешанная тревожная и депрессивная реакция.

\section{ОБСУЖДЕНИЕ РЕЗУЛЬТАТОВ}

Параллельные наблюдения проведены в России (Хабаровск) и Китае (Харбин) по идентичным методикам. В анамнезе обоих подростков выявлено наличие случаев психических расстройств у родственников. Это подтверждает теорию о том, что депрессивные расстройства генетически детерминированы [7, 19]. В клинической структуре ДР у подростков обнаружены сниженное настроение, утомляемость даже от низких нагрузок, утрата работоспособности, безразличие к прежним интересам и увлечениям и сниженная самооценка. Причем симптомы сниженной работоспособности и утомляемости более характерны для представителя азиатского этноса, а проявления ангедонии (отсутствие интересов и увлечений) - для славянского. В клиническом наблюдении у девушки-россиянки, как в целом у славян, суицидальные тенденции не зависели от тяжести депрессивных нарушений, суицидальная попытка обусловлена неадекватным типом личностного реагирования, спровоцированного употреблением алкоголя и семейными конфликтами $[1,3]$. Долгое пребывание в конфликтной ситуации служит фактором развития аутоагрессивного поведения, в том числе и суицидального. Стрессовая ситуация у респондента из азиатского этноса вызвала аутичнодепрессивную реакцию. Формирование этой психической патологии зависит от сочетания субъективной значимости психотравмирующей ситуации, тяжести заболевания, продолжительности и степени предрасположенности подростка к развитию депрессии. В формировании клинической картины ДР патопластическое и патогенетическое влияние ока- зывали дестабилизирующий психологический микроклимат в семье и тип воспитания $[3,14]$.

Исследование в динамике психического статуса в Китае не принято, поэтому сравнительный клинико-динамический анализ депрессивной симптоматики не проводился. Более того, в отличие от России в КНР отсутствует система диспансерного психиатрического наблюдения [5] и врач-психиатр не принимает участие в профилактических медицинских осмотрах детей и подростков в общеобразовательных учреждениях [4]. В то же время в КНР людей с отклонениями в физическом и психическом здоровье обычно стараются не только не отделять от процесса социального взаимодействия, но и делают всё возможное для их полноценного функционирования и социализации в обществе [21]. Это особенно важно для детей и подростков, страдающих психическими расстройствами.

\section{ЗАКЛЮЧЕНИЕ}

Клинико-психопатологическая структура подростковых депрессий зависит от этнокультуральных, личностно-психологических и социальных факторов риска и характеризуется следующим. Для российских подростков возрастной группы 15-19 лет характерна тенденция к формированию кратковременных и пролонгированных депрессивных реакций. В то время как у китайских подростков того же возраста более типичным является развитие депрессивного эпизода тяжелой степени без психотических симптомов.

Результаты собственного исследования показали преобладание у испытуемых тревожнодепрессивной симптоматики в форме диагностированного расстройства адаптации. Аффективные расстройства представляют собой гетерогенную группу, а механизмы их развития - комплексное нарушение функциональной активности системы нейрогуморальной регуляции, поддерживающей процессы жизнедеятельности. Необходимо дальнейшее изучение патогенеза аффективной патологии с учетом нарушений основных нейрогуморальных параметров при ДР и их корреляции с клинико-динамическими характеристиками, а также динамических изменений основных нейрогуморальных факторов при антидепрессивной терапии с целью её оптимизации. При этом значимая роль в формировании депрессивных состояний у детей и подростков принадлежит психологическому микроклимату в семье и типам этнокультурального воспитания.

Культуральным нормам Китая соответствует гиперпротекция, а российские подростки, воспитание которых проходило по типу гипопротекции, чаще пребывают в состоянии перманентного конфликта, что способствует развитию хронической психотравмирующей ситуации и суицидоопасного поведения. Изучение такого контингента дает возможность выявить клинические, лич- 
ностно-психологические и социальные факторы риска для разработки превентивных мероприятий.

Недостаточная психопрофилактическая помощь населению, низкая информированность по вопросам психопрофилактики и психогигиены способствуют утяжелению и хронизации психической патологии, что указывает на важную роль превентивного выявления, ранней диагностики и оказания своевременной помощи в снижении частоты депрессивных расстройств и подростковых суицидов.

\section{КОНФЛИКТ ИНТЕРЕСОВ}

Отсутствуют потенциальные и явные конфликты интересов авторов, связанные с публикацией материалов данной статьи.

\section{ИСТОЧНИК ФИНАНСИРОВАНИЯ}

Исследование выполнено при финансовой поддержке РФФИ в рамках научного проекта № 19-013-00018.

\section{СООТВЕТСТВИЕ ПРИНЦИПАМ ЭТИКИ}

Исследование соответствует этическим стандартам, разработанным в соответствии с Хельсинской декларацией ВМА. Субъекты исследований дали письменное информированное согласие в соответствии с Хельсинкской декларацией, подтвержденное протоколом заседания этического комитета Хабаровской краевой психиатрической больницы (протокол № 7/1/19 от 3.11.2018 г.) и Первого специализированного госпиталя Харбина (протокол № 18 от 14.01.2021)

\section{БЛАГОДАРНОСТИ}

Авторы благодарны Сунпэй Чжану, способствовавшему сбору материала для публикации.

\section{ЛИТЕРАТУРА/REFERENCES}

1. Логинов И.П., Савин С.3., Солодкая Е.В. Сравнительный анализ распространения депрессивных расстройств у подростков России и КНР. Вопросы психического здоровья детей и подростков. 2019. T. 19, 3. C. 4-12. Loginov IP, Savin SZ, Solodkaya EV. Comparative analysis of the prevalence of depressive disorders in adolescents in Russia and China. Mental Health Issues for Children and Adolescents. 2019;19(3):4-12 (in Russian).

2. Логинов И.П., Савин С.З., Солодкая Е.В., Богданов Н.А., Сунпэй Чжан. Превентивное выявление депрессивных расстройств у подростков. Дальневосточный медицинский журнал. 2019. T. 2: 36-39. Loginov IP, Savin SZ, Solodkaya EV, Bogdanov NA, Songpei Zhang. Preventive detection of depressive disorders in adolescents. Far Eastern Medical Journal. 2019;2:36-39. doi: 10.35177/1994-5191-2019-2-36-39 (in Russian).

3. Логинов И.П., Солодкая Е.В., Савин С.3., Сунпэй Чжан, Ксиджин Ван, Юлю Лиу Фенгуй Ю. Трансграничное исследование ситуации психического здоровья среди подростков. Дальнево- сточный медицинский журнал. 2015. Т. 1. С. 37 40. Loginov IP, Solodkaya EV, Savin SZ, Songpei Zhang, Xijin Wang, Yulu Liu Fengui Yu. Crossborder study of the mental health situation among adolescents Far Eastern Medical Journal. 2015;1:37-40 (in Russian).

4. Логинов И.П., Солодкая Е.В., Чжан С., Ван К., Лиу Ю., Ю Ф., Ян Л., Джан Ж. Психическое здоровье подростков Харбина (КНР). Сибирский вестник психиатрии и наркологии. 2015. № 3 (88). C. 76-79. Loginov IP, Solodkaya EV, Zhang Congpei, Liu Yulu, Yu Fengyu, Yang Liying, Jiang Zhe. Mental health of adolescents from Harbin. Siberian Herald of Psychiatry and Addiction Psychiatry. 2015;3(88):76-79 (in Russian).

5. Логинов И.П., Солодкая Е.В., Савин С.3. Современные представления об этнических особенностях непсихотических депрессивных расстройствах в подростковом возрасте (транкультуральное исследование). Международный научно-исследовательский журнал. 2017. Т. 4-3 (58). C. 162-165. Loginov IP, Solodkaya EV, Savin SZ. Modern ideas about ethnic characteristics of non-psychotic depressive disorders in adolescence (transcultural study). International Research Journal. 2017;4-3(58): 162-165 (in Russian).

6. Панченко Е.А., Положий Б.С. Суицидальная ситуация среди детей и подростков в России. Российский психиатрический журнал. 2012. № 1. C. 52-56. Panchenko EA, Polozhy BS. Suicidal situation among children and adolescents in Russia. Russian Psychiatric Journal. 2012;1:52-56 (in Russian).

7. Положий Б.С. Концептуальная модель суицидального поведения. Суицидология. 2015. Т. 6, № 1 (18). C. 3-8. Polozhy BS. Conceptual model of suicidal behavior. Suicidology. 2015;6,1(18):3-8 (in Russian).

8. Calear AL, Christensen H, Freeman A, Fenton K, Busby Grant J, van Spijker B, Donker T. A systematic review of psychosocial suicide prevention interventions for youth. Eur Child Adolesc Psychiatry. 2016 May;25(5):467-82. doi: 10.1007/s00787015-0783-4

9. Diagnostic and Statistical Manual of mental disorders, fifth edition. American Psychiatric Association (APA) DSM-library. https://doi.org/10.1176/appi.books.9780890425596

10. Jones K.D. The Unstructured Clinical Interview. J Counselling \& Development. 2010;88:220-226. DOI: 10.1002 / j.1556-6678.2010.tb00013.x

11. Hamilton M. A rating scale for depression. J Neurol Neurosurg Psychiatry. 1960 Feb;23(1):56-62. doi: 10.1136/jnnp.23.1.56

12. Kessler RC, Bromet EJ. The epidemiology of depression across cultures. Annu Rev Public Health. 2013;34:119-38. doi: 10.1146/annurev-publhealth031912-114409

13. van Loo HM, de Jonge P, Romeijn JW, Kessler RC, Schoevers RA. Data-driven subtypes of major de- 
pressive disorder: a systematic review. BMC Med. 2012 Dec 4;10:156. doi: 10.1186/1741-7015-10156

14. O'Connor EA, Whitlock EP, Beil TL, Gaynes BN. Screening for depression in adult patients in primary care settings: a systematic evidence review. Ann Intern Med. 2009 Dec 1;151(11):793-803. doi: 10.7326/0003-4819-151-11-200912010-00007

15. Rohan KJ, Rough JN, Evans M, Ho SY, Meyerhoff J, Roberts LM, Vacek PM. A protocol for the Hamilton Rating Scale for Depression: Item scoring rules, Rater training, and outcome accuracy with data on its application in a clinical trial. J Affect Disord. $2016 \quad$ Aug;200:111-8. doi: 10.1016/j.jad.2016.01.051

16. Spitzer R.L., Williams J.B., Gibbon M., First M.B. Structured Clinical Interview for DSM-IV-TR Axis I Disorders, research version. New York: Biometrics Research, New York State Psychiatric Institute, 2002: 10 .

17. World Health Organization Mortality Database. World Health Organization. Available from: https://www.who.int> healthinfo> mortality_data (31. 01.2021)

18. Williams JB, Gibbon M, First MB, Spitzer RL, Davies M, Borus J, Howes MJ, Kane J, Pope HG Jr, Rounsaville B, et al. The Structured Clinical Interview for DSM-III-R (SCID). II. Multisite test-retest reliability. Arch Gen Psychiatry. 1992 Aug;49(8):630-6. doi: 10.1001/archpsyc.1992.01820080038006

19. Woodberry KA, Shapiro DI, Bryant C, Seidman LJ. Progress and Future Directions in Research on the Psychosis Prodrome: A Review for Clinicians. Harv Rev Psychiatry. 2016 Mar-Apr;24(2):87-103. doi: 10.1097/HRP.0000000000000109

20. Zimmerman M, Martinez JH, Young D, Chelminski I, Dalrymple K. Severity classification on the Hamilton Depression Rating Scale. J Affect Disord. 2013 Sep 5;150(2):384-8. doi: 10.1016/j.jad.2013.04.028

21. http://study.feloo.com/mind/zhuanti/zisha/175528. html [текст на китайском языке]

Поступила в редакцию 24.12.2020 Утверждена к печати 03.03.2021

Логинов Игорь Павлович, доктор медицинских наук, заведующий кафедрой психиатрии и наркологии, ФГБОУ ВО «Дальневосточный государственный медицинский университет».

SPIN-code: 2527-3028, AuthorID: 605711

Солодкая Евгения Валерьевна, ассистент кафедры психиатрии и наркологии, ФГБОУ ВО «Дальневосточный государственный медицинский университет». SPIN-code: 6057-1950, AuthorID: 793988

Савин Сергей Зиновьевич, кандидат технических наук, Тихоокеанский государственный университет. SPIN-code: 8241-1541, AuthorID: 100847

Солодкая Евгения Валерьевна, solodkaya@nm.ru 
For citation: Loginov I.P., Solodkaya E.V., Savin S.Z. Psychopathological manifestations and features of the course of depressive disorders in adolescents: transcultural clinical observations. Siberian Herald of Psychiatry and Addiction Psychiatry. 2021; 1 (110): 78-84. https://doi.org/10.26617/1810-3111-2021-1(110)-78-84

\title{
Psychopathological manifestations and features of the course of depressive disorders in adolescents: trans- cultural clinical observations
}

\author{
Loginov I.P.1, Solodkaya E.V.', Savin S.Z. ${ }^{2}$ \\ ${ }^{1}$ Far Eastern State Medical University \\ Muravyev-Amursky Street 35, 680000, Khabarovsk, Russian Federation \\ ${ }^{2}$ Pacific State University \\ Pacific Street 136, 680035, Khabarovsk, Russian Federation
}

\begin{abstract}
Introduction. The relevance of the problem of depressive disorders manifesting in adolescents is determined by their high prevalence, difficulty to recognize this pathology at the early stages of the disease, and high suicidal risk. Objective of the study: to identify and systematize within the framework of the multifactor concept the clinical, social and personal psychological triggers that contribute to formation of depressive disorders in adolescents. Methods: clinicalpsychopathological, clinical-psychological (using an interview questionnaire, including anamnesis data), clinical-dynamic, experimental-psychological, sociopsychological, observation method, method of back translation. The methodological approach was based on the principle of ethno-social-cultural determinism of the emergence and clinical course of depressive disorders, taking into account their characteristics in various national cultures. Results. Clinical variants of depressive syndrome were identified using the example of two clinical observations (an 18-year-old girl and a 19-year-old boy, mean age $18.5 \pm 0.5$ years). It was found that the formation of depressive symptoms of pathoplastic and pathogenetic influence was exerted by two main factors - an unfavorable psychological microclimate in the family and a destructive type of upbringing. The patients were diagnosed with adjustment disorder, mixed anxiety and depressive reactions. Conclusion. Two clinical observations of adolescent depressive disorders, carried out in Russia (Khabarovsk) and China (Harbin), showed that in the anamnesis of the examined adolescents, there was a family history of mental disorders in close relatives. A significant role in the formation of depressive states belonged to negative factors experienced by adolescents - long-term psychological discomfort and dissatisfaction in connection with the unfavorable atmosphere in the family, as well as the ethnic type of upbringing.
\end{abstract}

Keywords: depressive disorders, manifestations of adolescent depression, motives of suicidal behavior in adolescents, ethnocultural paradigm, comparative transcultural study (Russia and China), description and analysis of clinical cases.

Received December 24.2020

Accepted March 03.2021

Loginov Igor P., MD, Head of the Department of Psychiatry and Narcology, Far Eastern State Medical University, Khabarovsk, Russian Federation. SPIN-code: 2527-3028, AuthorID: 605711

Solodkaya Evgenia V., Assistant, Department of Psychiatry and Narcology, Far Eastern State Medical University, Khabarovsk, Russian Federation. SPIN-code: 6057-1950, AuthorID: 793988

Savin Sergey Z., Candidate of Technical Sciences, Pacific State University, Khabarovsk, Russian Federation. SPINcode: 8241-1541, AuthorID: 100847

Solodkaya Evgenia V., solodkaya@nm.ru 